\title{
Intensifying dialysis to optimize pregnancy outcome
}

Low blood urea nitrogen (BUN) concentrations and increased hemoglobin levels are the key to optimum fetal outcomes in pregnant women on hemodialysis, suggests a Japanese singlecenter study. "Increased or intensive dialysis to achieve predialysis maternal BUN levels $<48 \mathrm{mg} / \mathrm{dl}[17 \mathrm{mmol} / \mathrm{l}]$ along with increased doses of erythropoietin to ensure maternal hemoglobin levels $\geq 9.6 \pm 0.9 \mathrm{~g} / \mathrm{dl}[96 \pm 9 \mathrm{~g} / \mathrm{l}]$ should be the standard for pregnant women on hemodialysis," say Sai Subhodhini Reddy and Jean L. Holley in an accompanying commentary in Kidney International.

\section{4 ...maternal BUN levels correlated negatively with both gestational age and birthweight... 77}

Since 1971, when the first successful birth to a patient receiving long-term hemodialysis was reported, the rate of pregnancy in women on dialysis has been increasing-particularly among those undergoing nocturnal hemodialysis.
However, fetal outcomes in the dialysis population remain suboptimal, with $80 \%$ of infants being born prematurely.

Yukari Asamiya and colleagues reviewed data from 28 pregnant women who underwent dialysis at Tokyo Women's Medical University Hospital during the period 1986-2007. The majority of women had been receiving regular hemodialysis since before conception. Pregnancy resulted in spontaneous abortion in four cases, stillbirth in one case, neonatal death in three cases and infant death in two cases; cesarean section was performed in 9 of 24 deliveries (37.5\%). A total of 18 patients $(64.3 \%)$ gave birth to live infants who survived for $\geq 1$ year. Consistent with previous data, $92 \%$ of births occurred before term.

Analysis revealed that mean BUN and serum creatinine levels from week 12 until delivery were significantly lower in the women whose infants lived for $\geq 1$ year than in the women whose pregnancies were unsuccessful $(16 \mathrm{mmol} / \mathrm{l}$ versus $24 \mathrm{mmol} / \mathrm{l}$ and $592 \mu \mathrm{mol} / \mathrm{l}$ versus $796 \mu \mathrm{mol} / \mathrm{l}$, respectively). By contrast, mean hemoglobin levels were significantly increased ( $96 \mathrm{~g} / \mathrm{l}$ versus $83 \mathrm{~g} / \mathrm{l})$ in the successful pregnancy group. Interestingly, maternal BUN levels correlated negatively with both gestational age and birthweight, key determinants of infant survival. A gestational age of 32 weeks and a birthweight of $1,500 \mathrm{~g}$ each corresponded to a BUN level of $17 \mathrm{mmol} / \mathrm{l}$.

The maternal BUN goal of $<17 \mathrm{mmol} / \mathrm{l}$ recommended by Asamiya et al. and by Reddy and Holley correlates well with the goal of $\leq 18 \mathrm{mmol} / \mathrm{l}$ suggested by previous retrospective studies. Asamiya's team hopes to test the findings of their study in a prospective fashion. In the meantime, they recommend that women on hemodialysis should advise their nephrologist before attempting to conceive, to ensure that optimal dialysis dose is achieved throughout pregnancy.

Chloë Harman

Original article Asamiya, Y. et al. The importance of low blood urea nitrogen levels in pregnant patients undergoing hemodialysis to optimize birth weight and gestational age. Kidney Int. 75, 1217-1222 (2009). 